\title{
STUDY OF AETIOLOGICAL FACTORS OF DEAFNESS IN CHILDREN UNDER COCHLEAR IMPLANT PROGRAM
}

\author{
Sampan Singh Bist ${ }^{1}$, Lovneesh Kumar², Vinish Agarwal ${ }^{3}$, Mukesh Sharma $^{4}$ \\ ${ }_{1}^{1}$ Professor and HOD, Department of Otorhinolaryngology, Himalayan Institute of Medical Sciences, Dehradun. \\ ${ }^{2}$ Assistant Professor, Department of Otorhinolaryngology, Himalayan Institute of Medical Sciences, Dehradun. \\ ${ }^{3}$ Assistant Professor, Department of Otorhinolaryngology, Himalayan Institute of Medical Sciences, Dehradun. \\ ${ }^{4}$ Assistant Professor, Department of Audiology, Himalayan Institute of Medical Sciences, Dehradun.
}

\section{ABSTRACT}

\section{BACKGROUND}

Normal hearing is the foundation for communication. Ability to listen is the first step towards speech development. Severe to profound hearing loss not only affects one's ability to hear, but also to learn and has in turn have far reaching consequences owing to one's inability to communicate effectively in society. Severe to profound hearing loss in children is common. Fortunately, majority of these children can benefit from cochlear implant.

\section{AIM}

The goal of the present study was to investigate the different hearing impairment aetiologies of patients worked-up for implantation in cochlear implant program.

\section{MATERIALS AND METHODS}

This was a retrospective study conducted in a tertiary care teaching centre from March 2013 to March 2016 of the deafened children who attended ENT OPD and worked-up under cochlear implant program and few of them underwent cochlear implantation. Present study included 68 hearing impaired children. Collected data was: age, gender, state of birth, clinical profile, hearing impairment aetiology and reason of not undergone cochlear implantation.

\section{RESULTS}

In present study total 68 children data were analysed in a study period, out of which $62(91.1 \%)$ were prelingually and 6 (8.8\%) were post-lingually hearing impaired. The most common cause of deafness in our study was unknown 34 (50\%). The second common cause was acquired $24(35.29 \%)$, followed by hereditary in $10(14.70 \%)$ children. In acquired causes of deafness perinatal risk factors in 8 (33.3\%) children followed by postnatal risk factors in 6 (25\%) children was the common cause for deafness; 26 (38.2\%) children first time reported to doctor for this problem between the age of 4-5 years. The main visiting region to the hospital of majority of children was unable to speak in 57 (83.8\%), while only $11(16.1 \%)$ children primarily brought for decrease or unable to hear. Out of 68 children only $18(26.4 \%)$ underwent cochlear implant, 50 (73.5\%) children did not undergo cochlear implantation, $8(11.7 \%)$ due to congenital anomalies and $42(61.7 \%)$ due to financial constraint.

\section{CONCLUSION}

The major aetiological factors that caused deafness in the studied children are unknown followed by acquired. Unknown aetiology prevailed as main cause, and this indicates the need to carrying out genetic studies in congenital sensorineural deafness with unknown cause to find out aetiological factor. Awareness programs for community and primary medical provider for early detection of hearing abnormality at ground level should be promoted, which will serve as sampling for future actions in the public health in India.

\section{KEYWORDS}

Hearing Loss, Aetiology, Cochlear Implantation.

HOW TO CITE THIS ARTICLE: Bist SS, Kumar L, Agarwal V, et al. Study of aetiological factors of deafness in children under cochlear implant program. J. Evolution Med. Dent. Sci. 2016;5(75):5546-5549, DOI: 10.14260/jemds/2016/1253

\section{INTRODUCTION}

Deafness is one of the most significant disabilities noted in our country. It is the second most common cause of disability in India. According to national data, nearly 63 million people

Financial or Other, Competing Interest: None.

Submission 10-08-2016, Peer Review 05-09-2016,

Acceptance 12-09-2016, Published 17-09-2016.

Corresponding Author:

Dr. Sampan Singh Bist,

Professor and HOD,

Department of Otorhinolaryngology,

Himalayan Institute of Medical Sciences,

Swami Rama Himalayan University, Jolly Grant,

Doiwala, Dehradun-248140,

Uttarakhand, India.

E-mail: sampanbist@yahoo.com

DOI: $10.14260 /$ jemds $/ 2016 / 1253$
$(6.3 \%)$ in our country suffer from significant auditory loss. ${ }^{[1]}$ Hearing impairment is one of the disorders which disable the individual in terms of communication, impacting different aspects of his/her life: emotional, social, psychological and intellectual. Hearing loss in children constitutes a considerable handicap, because it is an invisible disability and compromises optimal development and personal achievement of a child. The period from birth to 5 years of life is critical for the development of speech and language; therefore, there is need for early identification and assessment of hearing loss and early rehabilitation in infants and children. Cochlear implants are the treatment of choice for patients with severe to profound sensorineural hearing loss in both ears with a functioning auditory nerve.[2,3] A cochlear implant is a small, complex electronic device that can help to provide a sense of sound to a person who is profoundly deaf or severely hard of 
hearing. The implant consists of an external portion that sits behind the ear and a second portion that is surgically placed under the skin. An implant does not restore normal hearing. Hearing through a cochlear implant is different from normal hearing and takes time to learn or relearn. However, it allows many people to recognise warning signals, understand other sounds in the environment and enjoy a conversation in person and help to understand speech. Use of a cochlear implant requires both a surgical procedure and significant therapy to learn or relearn the sense of hearing and Speech-Language pathologists and audiologists are frequently involved in this learning process. The goal of the present study was to investigate the different hearing impairment aetiologies of patients worked-up for implantation in cochlear implant program and serves as sampling material for future preventive public health care actions.

\section{MATERIAL AND METHODS}

Present study included prelingually and postlingually deafened children, who attended ENT OPD and work-up for and few of them underwent cochlear implant in the Department of Otorhinolaryngology in a tertiary care teaching centre from March 2013 to March 2016. Inclusion criteria were children suffering from severe to profound hearing loss. Children who did not undergo complete battery of investigations were excluded from the study; 68 children, (age 1.8 yrs. - 09 yrs.) work-up for cochlear implantation and 18 underwent cochlear implant in the study period in cochlear implant program. A detailed history was obtained in reference to prenatal, perinatal and postnatal period to find out various risk factors for hearing loss. All children underwent complete audiological and radiological battery of investigations. The aetiological diagnosis was obtained by means of an interview carried with the parents, family members and on the basis of investigation reports. We approached relevant issues such as problems during pregnancy (prenatal factors), problems during delivery and birth of the baby (perinatal factors), problems during postnatal period, hereditary factors associated with the current disease, financial constraint and first reporting time to hospital for hearing problem and speech language development.

\section{OBSERVATIONS}

The study included 68 children, males contributing 40 (58.8\%) and females were $28(41.2 \%)$. The rural:urban ratio was $2: 1$. The age range in present study was 1.6 - 11 years (Fig. 1); 26 (38.2\%) children are presented at age group of 4-5 years followed by 19 (27.9\%) children between the age group of 3-4 years; 35 (51.4\%) children belongs to lower socioeconomic status followed by $24(35.2 \%)$ children from middle socioeconomic status family. In $46(67.6 \%)$ cases, there was home delivery which was assisted by local dais, while in 22 $(35.3 \%)$ cases delivery was in nearby hospital. In 7 (10.2\%) children there was no immunisation, while 36 (52.9\%) children had incomplete immunisation. Only 25 (36.7\%) children had followed regular schedule of immunisation.

The main visiting region to the hospital of majority of children was unable to speak in $57(83.8 \%)$, while only 11 (16.1\%) children primarily brought for decrease or unable to hear. Only $16 \quad(23.5 \%)$ children directly reported to otolaryngologist for hearing and speech problem, while remaining $52(76.4 \%)$ children referred by paediatrician for hearing evaluation and for delayed speech development. In the present study 68 children assessed, the most commonly found aetiology of deafness was the unknown type in 34 (50\%) children. The second common cause was acquired in 24 (35.2\%) children, followed by hereditary in 10 (14.7\%) children (Table 1). In unknown type of aetiology, majority of children shows normal growth curve except hearing and speech problem. The second most common cause of deafness in present study was acquired in $24(35.2 \%)$ children, which predominantly included perinatal risk factors in 8 (33.3\%), followed by postnatal risk factors in $6(25 \%)$ and prenatal in 3 (12.5\%) children (Table 2). Considering the prenatal risk factors, it was observed that Infection and ototoxic drug history was the most common prenatal risk factor. There was one patient who had congenital rubella. Considering the perinatal factors, it was observed that low birth weight, birth asphyxia and prematurity along with home delivery were the important risk factors.

Meningitis and hyperbilirubinaemia in neonatal period were the predominant postnatal factors; $10(14.7 \%)$ children had family history of hearing impairment, out of them $2(20 \%)$ children had paternal and $8(80 \%)$ children had sibling factor. In present study, $62(91.1 \%)$ children were diagnosed as prelingual and $6(8.8 \%)$ children were diagnosed as postlingual hearing impaired. In postlingual group, all 5 (83.3\%) children develop deafness following meningitis while in $1(16.6 \%)$ child following head injury. Out of 68 children only 18 (26.4\%) underwent cochlear implant, 50 (73.5\%) children did not undergo cochlear implantation, $8(11.7 \%)$ due to congenital anomalies and $42(61.7 \%)$ due to financial constraint. Hearing aid with subsequent speech and language training was recommended all those children who had not undergone cochlear implantation.

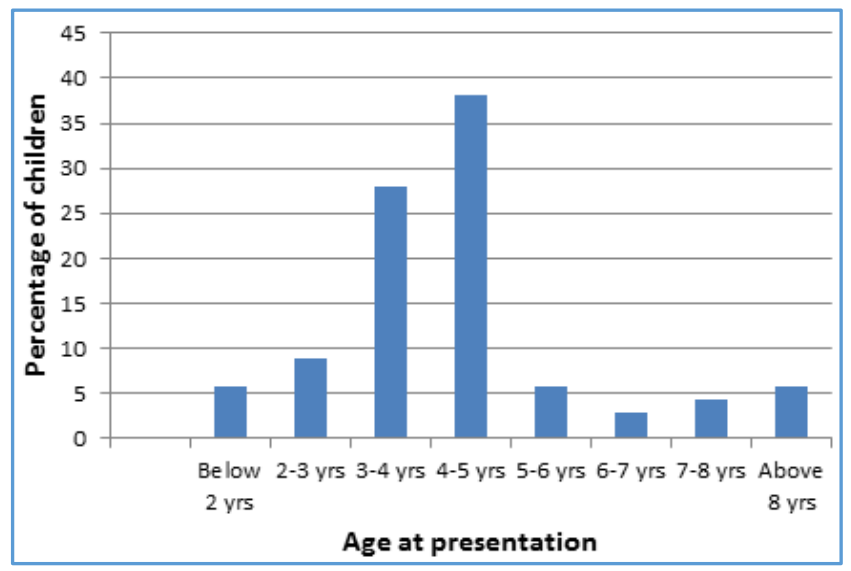

Fig. 1: Showing Age of Children Attending with Deafness

\begin{tabular}{|c|c|c|}
\hline Aetiological Factors & No. of Patients & $\%$ \\
\hline Unknown & 34 & 50 \\
\hline Acquired & 24 & 35.29 \\
\hline Hereditary & 10 & 14.70 \\
\hline Total & 68 & 100 \\
\hline \multicolumn{3}{|c|}{ Table 1: Aetiological Factors for Deafness $(n=68)$} \\
\hline
\end{tabular}

\begin{tabular}{|c|c|c|}
\hline Causes of Hearing Loss & No. of Patients & $\%$ \\
\hline Prenatal & 3 & 12.5 \\
\hline Perinatal & 8 & 33.33 \\
\hline Postnatal & 6 & 25 \\
\hline Prenatal + perinatal & 4 & 16.66 \\
\hline Prenatal + perinatal + postnatal & 3 & 12.5 \\
\hline Total & 24 & 100 \\
\hline
\end{tabular}




\section{DISCUSSION}

Hearing impairment is a serious, but grossly neglected condition in developing countries including India. The statistics are staggering - 360 million people in the world suffer from disabling hearing loss. This constitutes a substantial $5.3 \%$ of the world's population. The prevalence and incidence of hearing impairment in India also are substantially high. The high burden of deafness globally and in India is largely preventable and avoidable. The prevalence of deafness in South-East Asia ranges from $4.6 \%$ to $8.8 \%$. In India, 63 million people (6.3\%) suffer from significant auditory loss. Four in every 1000 children suffer from severeto-profound hearing loss. With over 100,000 babies that are born with hearing deficiency every year. The estimated prevalence of adult onset deafness in India was found to be $7.6 \%$ and childhood onset deafness to be $2 \% .{ }^{[1]}$ The National Sample Survey 58th round (2002) surveyed disability in Indian households and found that hearing disability was the 2nd most common cause of disability and top most cause of sensory deficit. In urban areas, loss was $9 \%$ of all disability and in rural areas it was $10 \%$. It was estimated that the number of person with hearing disability per 100,000 persons was 291 ; it was higher in rural (310) compared with urban regions (236). In the same survey, about $32 \%$ of the people had profound (person could not hear at all or could hear only loud sounds) and $39 \%$ had a severe hearing disability (person could hear only shouted words). The survey results revealed that about $7 \%$ of people were born with a hearing disability. About $56 \%$ and $62 \%$ reported the onset of hearing disability at $\geq 60$ years of age in the rural and urban areas, respectively.

The incidence of hearing disability during that year was reported to be $7 / 100,000$ population. The magnitude of milder degrees of hearing loss and unilateral hearing loss would be larger than these estimates for bilateral hearing loss.[4] In the present study, we analysed 68 children who enrolled in the cochlear implant program in last three years. The age range was 1.6 years - 11 years. Males contributing 40 (58.8\%) and females were $28(41.2 \%)$. In a study by Calhau ${ }^{[5]}$ male-tofemale ratio was 1.66 with males contributing $62.5 \%$ and females were $37.5 \%$, while in other study of 70 cases by Iype ${ }^{[6]}$ male-to-female ratio was 1.06:1. Our study also shows similar findings of gender distribution given as from national and international studies.[7] There is wide variation across the globe in the incidence and prevalence of childhood hearing loss and its possible aetiology. In the present study, the aetiological diagnosis was established by a detailed history to find out various risk factors for hearing loss and complete audiological along with radiological battery of investigations in all children. Among the 68 children studied, we found three major aetiological factors for the hearing loss. Even with a detailed history and relevant investigation, the most commonly found aetiological cause of hearing loss in present study was the unknown factor, which constitute $50 \%$ of studied children. Different other studies performed on aetiological cause of deafness shows unknown factor as most common cause of hearing loss in children and adults, hence present study results are similar to prior studies which shows $44 \%, 34.3 \%$ and $31.9 \%$ respectively as most common cause of hearing loss in their studies. $[8,9,10]$ The second most factor found was acquired in $35.2 \%$ children and third factor we found was hereditary in $14.7 \%$ of the children analysed for hearing loss.
The second most common cause of deafness in present study was acquired in $24(35.2 \%)$ children, which predominantly included perinatal risk factors in 8 (33.3\%) followed by postnatal risk factors in $6(25 \%)$ and prenatal in 3 $(12.5 \%)$ children. Considering the prenatal risk factors, it was observed that infection and ototoxic drug history was the most common prenatal risk factor. There was one patient who had congenital rubella. Considering the perinatal factors it was observed that low birth weight, birth asphyxia and prematurity along with home delivery were the important risk factors. Meningitis and hyperbilirubinaemia in neonatal period were the predominant postnatal factors. Fraser[11] in 1960 from U.K. reported that in $70 \%$ patients, the aetiology was congenital and in $30 \%$ it was acquired. Strauss ${ }^{[12]}$ in 1990 from USA reported that the probable cause of congenital deafness in their patients were toxoplasmosis $(10 \%-15 \%)$, rubella (33\%) and cytomegalovirus (33\% - 48\%). He further observed that with introduction of immunisation program, the incidence of disease has decreased. As reported by Martin and Davis, the most frequent cause of acquired deafness in childhood was meningitis[13,14] and according to Dodge ${ }^{[15]} 5 \%$ to $35 \%$ of the patients with bacterial meningitis develop permanent sensorineural hearing loss. In a study carried out by Iype ${ }^{6]}$ in which prenatal risk factors were identified in $45.71 \%$, perinatal factors were found in $71.42 \%$. Birth asphyxia predisposed by prematurity and low birth weight was the most common perinatal risk factor.

Majority of their neonatal group had jaundice requiring phototherapy and had delayed motor or personal social development. Bergman[16] found higher incidence of hearing loss in preterm babies than normal, because of prolonged hypoxia or acidosis. In present study $10(14.7 \%)$ children had family history of hearing impairment, out of them 2 (20\%) children had paternal and $8(80 \%)$ children had sibling factor. In study by Singh[17] also reported $10.8 \%$ cases of familial deafness. Approximately $50 \%$ of congenital deafness is inherited and hearing loss has been described in over 400 syndromes.[18] A large study reported that of 25,000 newborns screened, 8.1 percent fulfilled high-risk criteria for permanent childhood hearing loss[19]; $95 \%$ of babies admitted to NICU for more than 48 hours are more likely to develop permanent hearing loss ( $>50 \mathrm{dBHL}$ ) compared to those who did not require NICU admission.[14] A presence of family history with early permanent childhood deafness increases the prevalence by 14 fold.[20] The 2000 Joint Committee on Infant Hearing has recommended that infants with at least 1 of the risk indicators for progressive or delayed-onset hearing loss who may have passed the hearing screening should, nonetheless, receive audiological monitoring every 6 months until 3 years of age.[21] In present study, 26 (38.2\%) children are presented at age group of $4-5$ years followed by $19(27.9 \%)$ children between the age group of 3-4 years.

The causes of hearing loss are probably low socioeconomic condition leading to poor hygienic living condition and predisposition to ear infections, maternal infections and diseases during pregnancy and delivery, last but not the least is illiteracy. Ways and means to tackle this problem: Population awareness must be created regarding consequences of this disability. BERA machines should be installed in peripheral hospitals, which can detect pathologies in new-borns. BERA is an effective screening tool in the evaluation of hearing in new-borns with a high sensitivity and 
specificity. Cochlear implants are advisable whenever possible taking into consideration the economic condition of the patient. Speech therapy should be given by a qualified personnel. Living standard and economic condition should be improved in general. This is possible only with the help from the government. Social education must be given to educate the masses. It is important to note that without hearing a child cannot develop speech and language. Hence, the aim should be to recognise deaf child before the age of 1 year, because from 1 to 3 years onward babies start hearing the speech. Unfortunately, hearing loss is often not detected until a child is 2,3 or even 4 years old, especially in rural areas due to the poor awareness about deafness and its relation with speech and language development as well as lack of infrastructure such as the non-availability of ENT surgeon, audiologist, audiological equipment and speech therapist.

\section{CONCLUSION}

The major aetiological factors that caused deafness in the studied children are unknown followed by acquired. Unknown aetiology prevailed as main cause and this indicates the need to carrying out genetic studies in congenital sensorineural deafness with unknown cause to find out aetiological factor. Awareness programs for primary medical provider for early detection of hearing abnormality by which we can diagnose the cases early, then manage them with hearing aid and with the help of highly advanced technology like cochlear implants along with speech therapy. Public awareness at ground level should promote which will serve as sampling for future actions in the public health in India.

\section{REFERENCES}

1. Garg S, Chadha S, Malhotra S, et al. Deafness: burden, prevention and control in India. Natl Med J India 2009;22(2):79-81.

2. Nikolopoulos TP, Dyar D, Gibbin KP. Assessing candidate children for cochlear implantation with the Nottingham children's implant profile: the first 200 children. Int J Pediatr Otorhinolaryngol 2004;68(2):127-35.

3. Cullen RD, Higgins C, Buss E, et al. Cochlear implantation in patients with substantial residual hearing. Laryngoscope 2004;114(12):2218-23.

4. Singh V. Hearing in India: all aspects. Otolaryngol Online J 2015;5(1):39-70.

5. Calhau CM, Lima LR, Reis AM, et al. Etiology profile of the patients implanted in the cochlear implant program. Brazilian Journal of Otorhinolaryngology 2011;77(1):13-8.

6. Iype EM, Sasikumaran S, Devi SI. A clinical study on congenital and neonatal deafness. Indian Journal of Otolaryngology and Head and Neck Surgery 2000;52(3):242-5.

7. Egeli E, Ciçekci G, Silan F, et al. Etiology of deafness at the yeditepe school for the deaf in Istanbul. Int J Pediatr Otorhinolaryngol 2003;67(5):467-71.
8. Walch C, Anderhuber W, Köle W, et al. Bilateral sensorineural hearing disorders in children: etiology of deafness and evaluation of hearing tests. Int J Pediatr Otorhinolaryngol 2000;53(1):31-8.

9. Uus K, Davis AC. Epidemiology of permanent childhood hearing impairment in Estonia, 1985-1990. Audiology 2000;39(4):192-7.

10. Billings KR, Kenna MA. Causes of pediatric sensorineural hearing loss: yesterday and today. Arch Otolaryngol Head Neck Surg 1999;125(5):517-21.

11. Fraser GR, Froggatt P, James TN. Congenital deafness associated with electrocardiographic abnormalities, fainting attacks and sudden death. Quart J Med 1964;33:361-85.

12. Strauss M. Human cytomegalovirus labyrinthitis. American Journal of Otolaryngology 1990;11(5):292-8.

13. Martin JA. Aetiological factors relating to childhood deafness in the European community. Audiology 1982;21(2):149-58.

14. Davis A, Wood S. The epidemiology of childhood hearing impairment: factors relevant to planning of services. British Journal of Audiology 1992;26(2):77-90.

15. Dodge PR, Davis H, Feigin RD, et al. Prospective evaluation of hearing impairment as a sequela of acute bacterial meningitis. The New England Journal of Medicine 1984;311(14):869-74.

16. Bergman L, Hirsch RP, Fria TJ, et al. Cause of hearing loss in the high-risk premature infant. The Journal of Pediatrics 1985;106(1):95-101.

17. Singh M, Gupta SC, Singla A. Assessment of deafmute patients: a study of ten years. Indian Journal of Otolaryngology and Head \& Neck Surgery 2009;61(1):1922.

18. Marazita ML, Ploughman LM, Rawlings B, et al. Genetic epidemiological studies of early-onset deafness in the U.S. school-age population. Am J Med Genet 1993;46(5):48691.

19. Kennedy CR, Kitmm L, Dees CD, et al. Controlled trial of universal neonatal screening for early identification of permanent childhood hearing impairment. Lancet 1998;352(9145):1957-64.

20. Fortnum H, Davis A. Epidemiology of permanent childhood hearing impairment in Trent region, 1985-1993. British Journal of Audiology 1997;31(6):409-46.

21. Year 2000 position statement: principles and guidelines for early hearing detection and intervention programs. Joint committee on infant hearing, American academy of audiology, American academy of pediatrics, American speech language hearing association and directors of speech and hearing programs in state health and welfare agencies. Pediatrics 2000;106(4):798-817. http://professional.asha.org. 